\title{
A ECONOMIA POLÍTICA DA TRANSFORMAÇÃO DO NORDESTE: de Furtado a Unger
}

\author{
Carlos Sávio Teixeira*
}

\begin{abstract}
Este artigo analisa duas propostas de reorganização estrutural da sociedade nordestina, elaboradas em momentos distintos, uma sob a liderança intelectual de Celso Furtado e a outra de Mangabeira Unger. Argumenta que ambas partem da premissa de que o enfrentamento dos graves problemas da região mais desigual do país requer ousada reconstrução institucional, assim como a adoção de políticas públicas que objetivem enfrentar os constrangimentos estruturais da região e não apenas amenizá-los. Sustenta que a proposta que deu origem à SUDENE, capitaneada por Furtado, serviu de inspiração para a segunda empreitada mais recente, sendo as duas iniciativas baseadas em ideias que ultrapassam uma perspectiva meramente redistributivista.
\end{abstract}

PALAVRAS-CHAVE: Nordeste. Mudança estrutural. Reconstrução institucional. Celso Furtado. Mangabeira Unger.

Durante anos, a região Nordeste do Brasil foi vista pelo restante do país como aquela que representava, de maneira concentrada, os principais problemas da nação. A partir da última década, entretanto, o Nordeste experimentou um crescimento econômico maior que o restante do país e uma melhora em seus péssimos indicadores sociais, embora continue ostentando níveis de desigualdade socioeconômicos elevadíssimos. A questão é saber se essas mudanças são capazes de transformar, mesmo que progressivamente, a estrutura social da região mais desigual do Brasil, ou se apenas integram um movimento de redistribuição marginal de recursos que amenizam os efeitos extremos da miserabilidade, incapaz de impulsionar alterações institucionais que mexam com o fundo causal dos grandes desafios da sociedade nordestina. Este artigo faz uma análise de dois projetos

\footnotetext{
* Doutor em Ciência Política. Professor do Departamento de Ciência Política da Universidade Federal Fluminense (UFF). Campus do Gragoatá.

Rua: Professor Marcos Waldemar de Freitas Reis, Bl. O, Sala 313, São Domingos. Cep: 24210-201. Niterói - Rio de Janeiro - Brasil. carlos.savio.teixeira@gmail.com
}

de transformação do Nordeste, propostos sob a liderança intelectual de Celso Furtado e Mangabeira Unger, o que nos permite responder criticamente ao apelo do redistributivismo a que a região tem sido submetida recentemente.

Foi em meados do século passado que o Estado brasileiro começou a enxergar o Nordeste de maneira diferente e crítica. A causa dessa alteração muito se deveu ao fato de, pela primeira vez, ter sido formulada uma iniciativa abrangente para diagnosticar e enfrentar os desafios estruturais da região brasileira mais pobre e desigual. Durante o governo de Juscelino Kubitschek, foi criado o Grupo de Trabalho para o Desenvolvimento do Nordeste (GTDN) e, mais tarde, como seu produto, a Superintendência de Desenvolvimento do Nordeste (SUDENE). Celso Furtado, um paraibano possuído por enorme sentimento de tarefa, foi o principal responsável por essa mudança, que resultou, em grande medida, dos esforços de seu pensamento e de sua ação. Passados exatos cinquenta anos, outra empreitada intelectual e política voltada para tentar transformar o Nordeste foi novamente experimentada, dessa vez sob a liderança de Mangabeira 
Unger, durante o segundo governo Lula. ${ }^{1}$

Este texto tem por objetivo discutir os aspectos centrais desses dois esforços, semelhantes em seus propósitos e distintos em seus conteúdos, dedicando maior ênfase à iniciativa mais recente coordenada por Unger, tendo em vista sua relação direta com as questões e os processos presentes no debate sobre as mudanças ocorridas no Brasil nas últimas duas décadas. Portanto, o objetivo deste texto não é avaliar os resultados dessas iniciativas, mas as suas ideias norteadoras. Para atingir sua meta, o texto se divide em duas partes: a primeira faz uma breve recapitulação do contexto de surgimento de cada iniciativa e de seu respectivo sentido político. Em seguida, ainda na primeira parte, apresenta e discute o conteúdo das propostas de Furtado e de Unger, procurando realçar suas diferenças. Na segunda parte, analisam-se dois grandes eixos temáticos que orientaram as proposições de Unger para o Nordeste e, principalmente, como elas se encaixam no nosso atual debate programático: a questão da reorganização do Estado e as implicações das políticas sociais para as mudanças na estrutura da sociedade brasileira.

\section{POLÍTICA À BASE DE IDEIAS: da luta pela industrialização à proposta de institucionalização de uma economia de pequenos e médios empreendedores}

Num momento histórico como o atual, marcado por profundo desencanto com a política e pelo descrédito em ideias transformadoras, o exame de duas iniciativas cuja característica principal é a esperança em mudanças de longo alcance deixará o leitor, dependendo de sua natureza ideoló-

${ }^{1}$ Celso Furtado foi o Coordenador do GTDN e o primeiro Superintendente da SUDENE, criada em dezembro de 1959. Dessas experiências resultaram vários documentos. Dois, em particular, têm grande importância programática: o livro A Operação Nordeste e o texto Uma Política de Desenvolvimento Econômico para o Nordeste, ambos escritos por Furtado. No caso do segundo momento analisado, sob a liderança de Mangabeira Unger à frente da Secretaria de Assuntos Estratégicos da Presidência da República, o documento fundamental foi "O Desenvolvimento do Nordeste como Projeto Nacional", elaborado em 2009 . gica, com nostalgia ou com alívio. O fato é que tanto o projeto de Furtado quanto o de Unger têm um conjunto de aspectos que os aproximam, apesar do hiato de meio século separando-os. Em primeiro lugar, são esforços que partem da premissa de que as ideias, no sentido de uma interpretação teórica da realidade, contam na política. E de que a tarefa de um pensador não é só diagnosticar os males de uma dada realidade, mas também propor soluções e tentar organizar o futuro. Em segundo lugar, os dois esforços compartilham a premissa de que a forma paradigmática da mudança na história não é nem a revolução nem o reformismo, mas a reconstrução institucional, entendida como um conjunto de passos cumulativos rumo a uma determinada direção. E que, portanto, não há substituto ao Estado na tarefa de conduzir a transformação institucional de uma determinada estrutura, em especial se ela for marcada por fortes desigualdades. Em terceiro lugar, coloca-se a conclusão de que não há solução para os problemas da sociedade brasileira sem o enfrentamento da questão Nordeste.

Mas, por outro lado, embora os dois projetos se assemelhem em muito de seus objetivos e de suas premissas, há também diferenças de ênfases e de substância entre eles, tanto nos diagnósticos como nas propostas. Furtado apostava na reprodução, no Nordeste, do tipo de industrialização característica do Sudeste e era descrente na possibilidade de uma agricultura modernizada na região do semiárido - algo compreensível para as condições tecnológicas de meio século atrás. Unger, ao contrário, foi um crítico do que designou de "são paulismo", o desenvolvimento baseado em grandes indústrias de produção em massa, e defendeu o apoio decidido do Estado, com seus recursos e seu poder de estruturação, à construção de uma economia de pequenos e médios empreendedores, assim como vislumbrou a possibilidade de construção, no Nordeste, de uma agricultura vanguardista, beneficiária de avanços tecnológicos e arranjos institucionais inovadores.

O Nordeste foi "inventado" oficialmente como realidade espacial durante a ditadura do Estado Novo, quando o Instituto Brasileiro de Ge- 
ografia e Estatística (IBGE) definiu em cinco a composição geográfica das regiões brasileiras, no âmbito do esforço do governo Vargas para construir e consolidar a identidade da nação. Até então, o Nordeste figurava na agenda política em função basicamente dos períodos de secas que o assolavam e dos diversos planos governamentais para combatê-las, dentro da agenda da chamada "política hidráulica”. O seu apelo ainda era ligado a uma questão da natureza (clima e solo) e, também, circunscrito ao plano regional. A partir do acelerado processo de transformação da economia e da sociedade brasileira decorrente da industrialização por substituição de importações, as consequências dessa modernização começaram a mudar também a forma de entender o problema regional. Será nesse contexto que surgirá o mais notável, em alcance simbólico e influência política, projeto de ação governamental pensado e estruturado a partir da compreensão de que a questão regional é, fundamentalmente, uma questão nacional.

Celso Furtado reorienta decisivamente o debate sobre o Nordeste ao interpretar teoricamente, de maneira clara e contundente, a relação de complexa interdependência na esfera econômica entre os planos regional e nacional. O relatório final do GTDN se inicia com a seguinte afirmação: "A disparidade de níveis de renda existente entre o Nordeste e o Centro-Sul do país constitui, sem lugar a dúvida, o mais grave problema a enfrentar na etapa presente do desenvolvimento econômico nacional". A tese de Furtado é a de que a consolidação da industrialização do Sudeste, sediada principalmente em São Paulo, foi um processo que não levou em consideração a desigualdade regional, nem muito menos o seu possível aumento. E mais: o não enfrentamento desse grave dualismo poderá acarretar problemas como o acirramento de rivalidades regionais que, no limite, podem colocar em xeque o próprio desenvolvimento nacional. ${ }^{2}$

\footnotetext{
${ }^{2}$ Muitos críticos de "esquerda” das teses de Furtado sobre a "questão regional" nordestina assinalaram o quanto elas eram decisivamente marcadas por uma perspectiva nacionalista. Por nacionalista se entende, nesses casos, a não percepção de que as determinações objetivas de natureza econômica externa restringem as possibilida-
}

Furtado entendia que, no fundo, a questão era, em grande parte, de racionalização dos recursos já disponibilizados para o Nordeste pelo Estado brasileiro. Assim, a tarefa era tornar o montante dos investimentos canalizados capazes de transformar progressivamente a economia regional que mais sofria com a industrialização em curso, de maneira tal que a questão da seca, então central no debate sobre o Nordeste, não mais se colocasse como um problema estrategicamente relevante. A sua proposta era a de que o Estado brasileiro deveria se empenhar na tarefa de ajudar a constituir uma burguesia nordestina capaz de levar a cabo a industrialização da região, voltada para uma produção destinada ao mercado da própria região, que, como decorrência disso, teria condições de derrotar politicamente as oligarquias rurais e abrir caminho para o processo de democratização social do Nordeste. ${ }^{3}$

Além de se confrontar contra as principais teses da época - tanto as que enxergavam, na política de substituição de importações, o único caminho para a nossa modernização (embora reconhecessem que essa política gerou acelerada industrialização, crescimento econômico e a "internalização dos centros de decisão", ao custo do aumento das disparidades regionais), quanto as que criticavam

des e a eficácia de planejamento do Estado, ou o quanto a questão regional é usada como um veículo discursivo para possibilitar a institucionalização do capitalismo. São exemplos dessa visão um livro famoso de Francisco de Oliveira, da década de 70 (Oliveira, 1977), e vários textos reunidos em livro organizado por Silvio Maranhão nos anos 80 (Maranhão, 1982). Aqui, como em outros casos similares, é interessante notar como, depois dos anos 90, e, em particular, do governo do sociólogo da USP, Fernando Henrique Cardoso, muitos dos críticos de "esquerda" de Furtado passaram a reabilitá-lo, senão integralmente, pelo menos parcialmente.

${ }^{3}$ Furtado também foi, anos mais tarde, um dos responsáveis, na condição de ministro do Planejamento do governo João Goulart, pela síntese programática de um dos grandes e mais originais esforços de manejo do aparato estatal na construção de "[...] um 'desenvolvimentismo nacional, popular e igualitário’, que nasceu no campo do debate das ideias e das mobilizações sociais, muito mais do que no gerenciamento dos governos, nos anos 50 se tangenciou o 'desenvolvimentismo conservador', no campo das ideias e das alianças, e no início da década de 60 propôs uma reforma do projeto que incluía, ao lado da industrialização e do crescimento econômico acelerado, o objetivo da democratização do acesso à terra rural e urbana, à renda, ao sistema educacional e também ao sistema político. Uma alternativa que foi sintetizada, em parte, pelo Plano Trienal de Celso Furtado de 1963, e que foi bloqueada pelo golpe militar de 1964." (Fiori, 2004). Para uma interpretação acerca da teoria sociopolítica de Furtado e sua compreensão da relação entre democracia e desenvolvimento, ver Cepeda (2001). 
os rumos da política econômica de Kubitschek, por considerá-la o meio de aprofundamento do capitalismo e de suas vicissitudes características no Brasil -, os diagnósticos e as propostas de Furtado também batiam de frente com o discurso dominante no interior das elites do Nordeste, que diziam ser a seca o problema central da região a exigir combate. "Afirmar que a seca não é a causa do problema nordestino fazia Furtado se chocar com o núcleo da política regional, na época, mais importante para o Nordeste - que era a política hidráulica." (Bacelar, 2000, p. 76). ${ }^{4}$

O mais importante na compreensão da disfuncionalidade da compensação hidrológica era que as frentes de trabalho serviam para a manutenção de um exército de reserva disponível para a grande propriedade. A produção do algodão era a atividade dominante, em regime de "meia", por pequenos produtores que também produziam para subsistência. A seca tornaria mais cara a manutenção dessa força de trabalho barata, não fosse a socialização propiciada pelas frentes de trabalho, que, pelo lado político, anestesiavam o potencial político desestabilizador de elites da seca.

Nesse sentido, outro elemento importante do projeto de Furtado para o Nordeste, portanto, tem relação direta com a sua visão sobre o problema do semiárido. Ela se concentra basicamente sobre duas principais questões: uma relativa às condições climáticas e de solo, e outra, mais importante e decisiva, relativa à sua organização produtiva baseada em agricultura e pecuária de subsistência, desvinculada de relações mercantis, como se percebe na seguinte passagem: "O sistema econômico que existe na região semiárida do Nordes-

${ }^{4}$ A economista pernambucana destaca a relação entre as dimensões econômica e política da questão: “O relatório do GTDN mostra que a política hidráulica, em vez de atenuar as consequências econômicas e, sobretudo, as consequências sociais da seca, as exacerbava. Na medida em que salvava o gado e protegia a pecuária, que era a atividade hegemônica dos grandes proprietários da região, e não tocava na produção familiar e nem era destinada à maioria da populaçẫo da região, constituída de pequenos produtores rurais sem terra que viviam nos grandes latifúndios agropecuários, e cuja tendência demográfica era de crescimento, ampliava o impacto social de cada seca. Portanto, a cada seca se tinha mais gente nas frentes de trabalho destinadas aos 'flagelados'." (Bacelar, 2000, p. 76-77). te constitui um dos casos mais flagrantes de divórcio entre o homem e o meio, entre o sistema de vida da população e as características mesológicas e ecológicas da região.” (Furtado, 1959, p.30). Sua principal proposta para o encaminhamento da questão do semiárido era a - difícil, em sua avaliação-reestruturação produtiva de sua agropecuária e a expansão de sua fronteira agrícola através da incorporação do Sul do Maranhão ao Nordeste, para servir à colonização da população oriunda do semiárido.

A ideia de colonização do Maranhão por migrantes do semiárido nordestino se transformou em realidade através de um Decreto Presidencial que estabeleceu esse Estado como área sob a jurisdição da SUDENE. Mas a ideia teve de vencer muitas resistências. No bojo dessa luta, Furtado foi acusado de confusão teórica e até de desumanidade, por não levar em consideração o sofrimento da população do semiárido a ser transferida. Mas seus textos desmentem ambas as acusações:

É necessário frisar que, nas regiões para onde eles se deslocam, prevalecem condições de vida extremamente precárias. São regiões semi-isoladas, com grau mínimo de integração numa economia de mercado, com técnicas de trabalho e formas de organização da produção extremamente rudimentares - de maneira geral inferiores às que prevalecem na região semiárida. Deslocar populações nordestinas para essas regiões, sem antes modificar o sistema econômico que aí existe, é condenar essas populações a condições de vida de extremo primitivismo. Se bem não estejam sujeitas ao flagelo das secas, as regiões da periferia úmida maranhense, em razão de seu isolamento, constituem um sistema econômico ainda mais dependente de atividades de subsistência que o da região semiárida (Furtado, 1967, p. 77, Grifos nossos).

Um dos grandes temas de debate no interior da esquerda, nessa época, era a reforma agrária. No Nordeste, a questão teve grande impulso a partir do relativo impacto das Ligas Camponesas, que se desenvolveram principalmente sob a liderança do advogado e deputado socialista Francisco Julião. Mas Furtado não se deixou seduzir pelo movimento político e condicionou a proposta de divisão de terras à finalidade precípua de sua agenda 
programática: ajudar a aumentar substancialmente a oferta de alimentos para a própria região, o que, num primeiro momento, significava mexer somente com as terras do setor canavieiro da faixa úmida, e, no semiárido, com aquelas já beneficiadas pelo sistema de açudes. Já para a região do agreste, espaço de transição entre o litoral e o semiárido, sua ideia caminhava em sentido contrário, de certa reconcentração fundiária, já que, nessa zona, imperava significativa dispersão fundiária ${ }^{5}$ (Furtado, 1959, p. 57-65).

Uma das características distintivas do projeto encabeçado por Furtado foi a clareza com que distinguiu, de um lado, a definição do conteúdo do programa e, de outro, o agente institucional apto a desenvolvê-lo. A SUDENE, por exemplo, foi criada em 1959, como o desdobramento de um plano claramente delineado, cujas tarefas a executar necessitavam de uma agência como ela. ${ }^{6}$ Portanto, sua instituição original em nada se deveu ao conhecido método brasileiro de criar órgãos ou instrumentos de ação quando não se sabe ou não se quer enfrentar determinada questão, em especial quando ela apresenta, aos olhos dos políticos e burocratas envolvidos, riscos políticos. Esse foi o caso da recriação da SUDENE em 2007, durante o governo Lula, num ato de homenagem simbólica a

${ }^{5}$ Em uma entrevista de 2004, Furtado afirmou que “... quaisquer que hajam sido as intenções dos autores do golpe militar de 1964, o seu efeito principal foi, sem lugar a dúvida, a interrupção do processo de mudanças políticas e sociais, entre elas, em primeiro lugar, a construção que se iniciava de uma nova estrutura agrária em nosso país. Cabe acrescentar que o dano maior do golpe foi feito ao Nordeste, onde era mais vigoroso o movimento renovador em curso de realização e onde eram, e ainda são, mais nefastos os efeitos do latifundismo" (Furtado apud Bacelar, 2009, p. 41-42).

${ }^{6}$ Alguns autores chamaram a atenção para o fato de a SUDENE ter sido pensada com o objetivo de realizar, entre outras atribuições, o enfrentamento do grave problema federativo experimentado pelo Brasil que, ao copiar sem rebucos o modelo norte-americano, com o seu arcabouço legal definindo de maneira rígida as competências entre os entes federados, acabou por agravar ainda mais a nossa realidade marcada por profundas desigualdades regionais. Nesse sentido, a SUDENE foi uma instância que, na ausência de um "federalismo cooperativo", como propunha Furtado, fez as vezes de uma instituição capaz de superar os entraves da camisa de força de nosso federalismo e "[...] articular os interesses estaduais, produzindo assim, simultaneamente, cooperação regional e força política para atuar nas negociações no plano nacional" (Ismael, 2009, p. 243). Na segunda parte deste artigo, será feita uma análise de como a perspectiva do projeto encabeçado por Unger atualizou essa questão.
Celso Furtado e “atenção” a uma região para a qual o governo petista não tinha um projeto claro.

O projeto de Nordeste, defendido por Mangabeira Unger meio século depois da empreitada de Celso Furtado, também representou um esforço intelectual e político de colocar a questão "regional" no centro da agenda política nacional e no coração do processo decisório do Estado brasileiro. Foi formulado como um programa capaz de ser a expressão regional de um novo modelo de desenvolvimento que "ancore o social na maneira de organizar o econômico”, o que significa romper com o que Unger chamou de o "pobrismo”, característico das políticas socioeconômicas destinadas a apenas mitigar os efeitos da pobreza que atinge a maioria dos nordestinos. Nesse sentido, sua concepção foi deliberadamente pensada como uma alternativa às ideias reinantes a respeito do modo de realizar a inclusão social: ao invés de política social compensatória, que cumpre uma função importante em contexto de desigualdades tão fortes como o do Nordeste, mas uma política social que enfrente o dualismo ao invés de aceitá-lo e reproduzi-lo. ${ }^{8}$

${ }^{7}$ A SUDENE foi criada como órgão diretamente ligado ao Gabinete da Presidência da República e teve sua atuação relativamente empoderada segundo seus termos originais até o golpe militar de 64, quando foi incorporada ao Ministério do Interior, tendo suas funcões modificadas. Em 2001, no governo de Fernando Henrique Cardoso, foi extinta. Para uma análise quase biográfica acerca da SUDENE, ver Furtado, 1997 (segundo livro, cap. 3, 4 e 5). Para uma avaliação crítica a respeito da concepção teórica norteadora da SUDENE e de seus principais resultados, a partir de uma visão marxista fundada na ideia de que a questão regional não precede o problema de classe, ver Oliveira (1977), e, a partir de uma visão liberal fundada na ideia de que a questão da disparidade de renda regional não precede a disparidade de renda individual, ver Pessoa (1999).

${ }^{8}$ Minha hipótese é a de que essa iniciativa em relação ao Nordeste, liderada por Mangabeira Unger, foi inspirada na experiência de Celso Furtado na época da SUDENE. Mangabeira Unger sempre se mostrou um grande admirador de Furtado. Dias após a morte de Furtado, em 2004, escreveu um artigo (Unger, 2004b) de homenagem ao pensador paraibano, um "sertanejo curtido pelo mundo" como o definiu Gildo Marçal Brandão, no qual descrevia a tarefa que os sobreviventes tinham pela frente se quisessem levar adiante o legado de pensamento e acão do autor de A Dialética do Desenvolvimento. Quando a oportunidade apareceu, em 2008, durante sua participação no ministério de Lula, ele organizou uma iniciativa abrangente para a região, com o seu "Projeto Nordeste”. Em várias discussôes com lideranças políticas e com movimentos sociais sobre suas propostas para o Nordeste noticiadas pela imprensa, Unger citou o exemplo de Furtado - não como meio de legitimação de sua iniciativa, já que também teceu críticas a aspectos do ideário do economista cepalino. 
A crítica ao "pobrismo" pode ser encontrada, sem rodeios, no texto publicado pela Secretaria de Assuntos Estratégicos (SAE), que serviu de base para o projeto de Unger para o Nordeste: "A primeira ilusão é a do 'pobrismo': confiar, sobretudo no semiárido, em ações e em empreendimentos de escalas e de cunho artesanais - como os microempreendimentos e as pequenas cooperativas. Estas ações ocupam as pessoas mais pobres. Geram um pouco de renda. Ajudam a evitar o pior, ainda que - todos o reconhecem - não resolvam os reais entraves ao desenvolvimento sustentável e includente da região" (Unger, 2009, p. 8). A ideia subjacente é a de que política social compensatória, circunscrita às divisões rígidas entre as vanguardas e as retaguardas produtivas, não é capaz de reduzir as desigualdades extremas como as que existem no Nordeste e no Brasil.

Tal como Furtado, as propostas socioeconômicas de Unger para o Nordeste partiram de uma crítica à ideia de redistributivismo desacompanhada da reorganização das relações de produção, embora nenhum dos dois concebesse a reorganização das relações de produção da mesma maneira que os marxistas. Para Unger, por exemplo, o processo de reorganização de uma dada estrutura econômica é quase sempre resultado de reconstrução institucional ${ }^{9}$. Assim, a economia de mercado não encerra um conteúdo jurídico e institucional predeterminado, e, por isso, pode ser institucionalmente reinventada: a ideia geral é que o tipo de regime de propriedade e contrato que passou a caracterizá-la no Ocidente não reflete uma

${ }^{9}$ Uma das principais críticas de Unger ao pensamento social, tanto o de ambição crítica e transformadora como o de matiz conservador, diz respeito ao compartilhamento de uma forma equivocada de compreensão do que são as instituições e a estrutura da sociedade e, ainda, de suas relações: "O fetichismo institucional é a crença em que conceitos institucionais abstratos, como as ideias de democracia representativa, economia de mercado ou sociedade civil livre, têm uma expressão natural e necessária em um conjunto particular de estruturas legalmente definidas. $\mathrm{O}$ fetichismo estrutural é a contraparte de ordem superior do fetichismo institucional: a ideia de que, apesar de podermos ser capazes de revisar uma ordem institucional particular, e até mesmo de substituir, vez por outra, um sistema institucional por outro diferente, não podemos alterar o caráter da relação entre as estruturas institucionais e a liberdade dos agentes que as ocupam de contestar e transcender essas estruturas" (Unger, 1999, p. 91). lógica profunda de necessidades econômicas e sociais, mas, ao contrário, resulta de lutas e construções políticas. Somente um pensamento formado dentro de uma cultura intelectual marcada pela "necessidade falsa" acredita que os dispositivos institucionais da modernidade resultam de uma lógica social ou econômica predeterminada.

Para Unger, as estruturas de uma sociedade “[...] são o resultado de muitas sequências frouxamente interligadas de conflito social e ideológico, e não imperativos funcionais insuperáveis e determinados, que dirigem uma sucessão de sistemas institucionais indivisíveis" (Unger, 1999, p. 26). Portanto, para ele, esse movimento promove a quebra do clássico antagonismo entre reforma e revolução, pois o experimentalismo institucional proposto pode ser radical, a ponto de transformar as estruturas básicas da sociedade. Daí o seu caráter revolucionário. E fazê-lo lidando com uma parte dessa estrutura por vez, passo a passo, cumulativamente. Daí seu caráter reformista. Nesse contexto, campos intelectuais como o Direito e a Economia Política podem virar grandes aliados do método do experimentalismo institucional, pois são eles que lidam mais de perto com a realidade dos arranjos institucionais estabelecidos e podem reconhecer que esses arranjos integram um conjunto de possibilidades institucionais muito mais amplo, que inclui não só soluções do passado reprimidas ou descartadas como tendências divergentes dentro da ordem atual (Unger, 2004, p. 36-40).

Por isso, ele pensa na possibilidade de instituir, no Nordeste, uma economia de pequenos e médios produtores, operando por meio de uma mistura de organização cooperativa e atividade independente, cujo horizonte é a estruturação de uma sociedade baseada na descentralização da propriedade..$^{10}$

\footnotetext{
${ }^{10}$ A teoria de Unger “[...] propõe o desmembramento do direito de propriedade tradicional para atribuir seus componentes a diferentes tipos de titulares. Entre esses sucessores do proprietário tradicional estarão as empresas, trabalhadores, governos locais e nacional, organizações intermediárias e fundos sociais. Ele se opõe à reversão simples da propriedade privada convencional para a propriedade do Estado ou de cooperativas de trabalhadores, porque essa reversão apenas redefine a identidade do proprietário sem alterar a natureza da propriedade 'unitária'. Propõe uma estrutura de propriedade em três ní-
} 
O conjunto de propostas de Unger para o Nordeste se baseia também numa compreensão dos limites e das possibilidades da região. É o que, no texto O desenvolvimento do Nordeste como projeto nacional, chama de "premissas": 1) a constatação de que a ausência de um plano abrangente e sistemático para a região, desde o início dos anos 60 do século passado, abriu espaço para três processos degenerativos: a) a busca de incentivos e subsídios fiscais, b) a fixação em grandes obras físicas, como a transposição do Rio São Francisco, e c) a crença em "ilusões", como o "pobrismo" e o "são paulismo"; 2) a tentação de não enfrentar, de forma "direta e para valer, o problema do semiárido", refugiando-se no "pobrismo". Trata-se de uma situação ainda mais grave, porque, além da dimensão moral e econômica do desastre fruto desse abandono do semiárido, ela representaria grande desperdício das condições favoráveis à “... construção de regime social que privilegia a autonomia e a cooperação entre gente livre"; 3 ) a realidade de um "novo" Nordeste, marcada por um impressionante empreendedorismo dos "batalhadores" e por uma não menos impressionante "inventividade tecnológica popular". ${ }^{11}$

Se o núcleo duro da proposta de Unger para o Nordeste é a criação de uma sociedade e uma economia de pequenos e médios empreendedores e trabalhadores, por meio de um conjunto de ino-

veis: um fundo central de capital, criado pelo governo nacional democrático para tomar as decisões finais relativas ao controle social da acumulação econômica; os vários fundos de investimentos criados pelo governo e pelo fundo central de capital para aplicação de capital em bases competitivas; e tomadores primários de capital que serão as equipes de trabalhadores, técnicos e empreendedores" (Cui, 2001, p. 19).

${ }^{11}$ O livro Os Batalhadores Brasileiros, do sociólogo Jessé Souza, obra que é o resultado de uma pesquisa teórica e empírica abrangente realizada em todas as regiões do Brasil sobre o perfil sociológico dos principais tipos de empreendedores e trabalhadores que integram um grupo social que se tornou suporte das transformações do capitalismo brasileiro nas últimas décadas, mostra, em seu capítulo 7, a realidade da segunda premissa sugerida por Unger, assim como, de maneira geral, a situação do empreendedorismo típico da região. Esses "batalhadores" empreendedores e trabalhadores seriam o agente em que Unger deposita suas maiores esperanças e que deveria ser - e ainda não é - o principal destinatário das políticas públicas do Estado brasileiro. Na região Nordeste, a presença acentuada desses "batalhadores" é percebida como uma vantagem e mais um indicativo do tipo de política industrial, agrícola e social que deve ser destinada à região. Não por acaso, o livro conta com um prefácio de Unger. vações institucionais capazes de rearranjar a estrutura de sua vida social, o seu veículo são as políticas públicas do Estado brasileiro, em especial a industrial e a agrícola na esfera econômica, e, na esfera social, aquelas destinadas à capacitação educacional centrada no ensino e difusão de ciência e de tecnologia capazes de instrumentalizar o empreendedorismo emergente dos "batalhadores". Toda essa discussão levantada por Unger acerca das novas formas de economia de mercado é caracterizada pela ligação que sua perspectiva teórica postula entre os problemas institucionais e as práticas mais características da atual produção de vanguarda, chamada por especialistas de "pós-fordismo".

A relação da política industrial-e da política agrícola, analisada a seguir-com a reconstrução da economia de mercado, numa direção como a preconizada pelo projeto Nordeste proposto por Unger, cujo foco está nas pequenas e médias empresas, ${ }^{12}$ tem o seu ideário fundado na superação do "são paulismo". A passagem seguinte é ilustrativa:

A primeira tarefa é acelerar a passagem, que já começou no centro industrial do país, para além do Fordismo. A segunda tarefa, mais exigente e menos compreendida, é organizar travessia direta do pré-Fordismo para o pós-Fordismo, sem que o país todo tenha de passar pelo purgatório do Fordismo industrial. O Brasil todo - o Nordeste inclusive - não deve ter de primeiro virar a São Paulo de meados do século vinte para poder, depois, transformar-se em algo diferente. O Nordeste não é para ser versão tardia da São Paulo de meados do século passado. O Nordeste deve por sua própria originalidade a serviço da originalidade do Brasil, abrir novo caminho de desenvolvimento nacional (Unger, 2009, p. 9).

Para realizar essa obra, a política industrial preconizada por Unger tem duas dimensões: uma institucional e outra operacional. Na primeira, a questão se refere às formas de relacionamento entre os produtores entre si e entre os produtores e o Estado. Na relação entre os produtores, o ponto central é a

${ }^{12}$ Afirma Unger (2009, p. 12): “O foco da política industrial não deve ser nem as grandes empresas, de um lado, nem os microempreendimentos, de outro lado. São as pequenas e médias empresas as que devem merecer a atenção prioritária. É nelas que está a grande maioria dos empregos industriais. E é delas que resulta a maior parte do produto. Nisso, o Nordeste apenas acentua uma característica generalizada da economia brasileira”. 
organização do regime de "concorrência cooperativa”, como meio de resolver o problema clássico de acesso à escala das pequenas e médias empresas. Assim, elas, apesar de continuarem competindo no mercado, podem compartilhar recursos financeiros e tecnológicos que, isoladamente, não conseguiriam alcançar. Já na relação entre os produtores e o Estado, o ponto central é a fuga da escolha entre o modelo norte-americano, desenhado para regular as empresas à distância, por meio de agências, e o modelo do nordeste asiático, em que o Estado impõe, de cima para baixo, por meio de uma burocracia forte, o seu projeto. A proposta para o Brasil em geral, e para o Nordeste em particular, centra-se no avanço em direção a um modelo experimentalista e descentralizado como o “[...] sugerido pelo conceito, tipicamente brasileiro, de arranjos produtivos locais”13 (Unger, 2009, p. 14). Na segunda dimensão, a operacional, dois aspectos são fundamentais: 1) a atenção decisiva à oferta real e massificada de crédito e de tecnologia às pequenas e médias empresas, de forma a completar otrabalho de aconselhamento gerencial realizado pelo Serviço Brasileiro de Apoio às Micro e Pequenas Empresas (SEBRAE) junto a esse universo empresarial: ${ }^{14} 2$ ) a organização das empresas em rede, de maneira a sempre existir uma instituição "âncora" (empresa maior ou agência do governo local) em torno da qual as empresas menores ou as cooperativas de empresas menores passem a gravitar. ${ }^{15}$

A democratização da economia de mercado

${ }^{13}$ Esse conceito tem sido desenvolvido no Brasil sob a liderança intelectual dos economistas Helena Lastres e José Cassiolato, que têm se dedicado ao estudo teórico e empírico do universo das pequenas e médias empresas e da realidade dos arranjos produtivos locais (APLs). Ver, entre outros, os dois volumes da obra de Cassiolato; Matos; Lastres (2008).

${ }^{14}$ A literatura que trata dos desafios à institucionalização das pequenas e médias empresas é consensual em seu diagnóstico: "Barreiras ao crédito geram ineficiências alocativas e subtraem recursos de projetos de investimento, que podem oferecer as maiores taxas de retorno [...] Se empresas de longa existência ou maior porte tiverem maior facilidade de acesso ao crédito, enquanto novas firmas ou pequenas e médias empresas não têm, algumas dentre elas terão uma sobrevida além da expectativa, e a concorrência será reduzida. No mundo em desenvolvimento, este é um problema que se difunde e constitui um sério impedimento à criação de economias locais dinâmicas em torno de um setor de pequenas e médias empresas em expansão" (Mytelka; Farinelli, 2005, p. 367).

${ }^{15}$ No texto do projeto da SAE, há uma passagem em que se pode perceber como a realidade do Nordeste ajudou a reforçar muitas das proposições teóricas de Mangabeira no Nordeste brasileiro, sugerida acima pela política industrial voltada para o empreendedorismo emergente, se completa através de uma política agrícola. Na proposta da SAE, há um conjunto de elementos que apenas reproduz o consenso dominante acerca do conteúdo de uma política agrícola para o país, do qual, talvez, não participem apenas os setores da esquerda, que centra seu discurso na questão da reforma agrária. ${ }^{16}$

Assim como na política industrial, a dimensão institucional, geralmente negligenciada nas discussões sobre agricultura, ganha ênfase na proposta de política agrícola da SAE, tanto aquela destinada à agricultura irrigada como à voltada para a agricultura de sequeiro. O núcleo é a organização pelo Estado de quatro conjuntos de ações: comercialização, ajuda técnica através do extensionismo agrícola, em que o método da colaboração entre os entes federados seja decisivo, disseminação para os pequenos e médios produtores agrícolas dos instrumentos financeiros como os hedges, que protegem contra os riscos climáticos e econômicos que caracteristicamente recaem sobre a agricultura (e que hoje somente o agronegócio deles se beneficiam) e, por fim, reorganização dos mercados agrícolas para acabar com a fragmentação dos produtores frente aos fornecedores e compradores cartelizados. Tudo isso sob o seguinte princípio: "[...] quando o mercado não faz, o Estado (inclusive a Conab) tem de fazer

Unger: "A primeira dessas forças construtivas é um empreendedorismo emergente [...] Por exemplo, em Caruaru e Toritama, no interior de Pernambuco, veemse todas as etapas do capitalismo europeu, do século dezessete ao século vinte, coexistirem no mesmo lugar. Estão presentes num complexo de confecções que sobrevive longe dos grandes mercados consumidores e da matéria-prima. E que toma a forma não só de empresas médias, mas também de mais de dez mil empreendimentos caseiros - os chamados fabricos - que trabalham em regime de terceirização para aquelas empresas médias" (Unger, 2009, p. 11). Para uma análise de caso desse processo no Nordeste, ver Lourenço (2007).

${ }^{16}$ Fazem parte da proposta o reconhecimento da agricultura como dimensão fundamental de qualquer economia moderna e a necessidade de agregar à agricultura familiar características empresariais sem que isso implique a perda de seu vínculo com a policultura e com a propriedade descentralizada. Como decorrência, o esforço para agregar valor aos produtos do campo e a atenção aos problemas mais característicos da agricultura como a estrutura física (centrada basicamente no equacionamento do problema da irrigacão) e o financiamento. Mas a tudo isso a proposta de Mangabeira Unger acresce o objetivo de se "[...] construir classe média rural forte, como vanguarda de uma massa de lavradores pobres que virá atrás dela” (Unger, 2009, p. 15). 
como vanguarda do mercado" (Unger, 2009, p.16). ${ }^{17}$

Embora inovador e profundamente provocativo, o projeto de Unger parece equivocado em algumas partes. Talvez o seu principal problema seja confundir a correta compreensão dos limites das alternativas fordistas com a obrigação de instantaneamente superá-los. O fordismo já é forte no Nordeste, e não parece ser razoável que alternativas produtivas fordistas não possam ser uma parte da solução regional. No Nordeste, parece existir espaço até para o "pobrismo" durante certo tempo. Ou seja: embora o empreendedorismo flexível das pequenas e médias empresas que colaboram e concorrem, ao mesmo tempo, deva ser o nexo dinâmico de um projeto de desenvolvimento para o Nordeste, pode haver espaço e importância relativa para o fordismo - e o fordismo flexível, que não é a mesma coisa que dominou São Paulo. Em outras palavras, no Nordeste, talvez existam condições até para "maquiladoras". E isso sem comprometer o núcleo central da nova política, que é voltar os instrumentos do Estado para os clusters dos pequenos e médios empreendimentos dinâmicos.

Portanto, o núcleo do projeto de Mangabeira Unger para o Nordeste objetiva construir uma economia organizada de uma forma que reúna capital, tecnologia e trabalho, sem distribuir direitos permanentes e irrestritos a seu uso. Essa solução implica imaginar e experimentar instituições que expressem o antigo ideal, centrado no pequeno produtor independente, como uma alternativa prática ao capitalismo, conforme a tradição "socialista utópica" de pensamento, fundada na realização do progresso econômico e tecnológico e na democratização da estrutura social. ${ }^{18}$ Embora com conteúdo diferente, o projeto formulado por Unger se

${ }^{17}$ A proposta de Mangabeira Unger destaca também a importância da agricultura de sequeiro, apostando alto nas possibilidades do desenvolvimento tecnológico: "A agricultura de sequeiro não só exige tecnologia própria, de aproveitamento do solo, de experimentação com sementes e de adaptação à sazonalidade das chuvas, como também só se viabiliza, economicamente, com o avanço da industrialização rural. O conjunto de formas de agregação de valor no campo precisa ser maior, não menor, para a agricultura de sequeiro do que para a agricultura irrigada” (Unger, 2009, p. 15-16).

${ }^{18}$ Para uma visão geral sobre os fundamentos clássicos do pensamento da tradição socialista utópica e seus principais temas e questões, ver Teixeira (2002). inspirou na experiência anterior liderada por Celso Furtado e reviveu seu sonho de transformar a região-problema em exemplo de um caminho para toda a sociedade brasileira:

[...] ao mesmo tempo em que apresenta muitos dos problemas nacionais em sua forma mais concentrada, o Nordeste reúne muitos dos elementos indispensáveis às soluções nacionais, inclusive a força da identidade coletiva e o acúmulo dos vínculos associativos (o capital social). No Nordeste, mais do que em qualquer outra parte do país, o Brasil afirma sua originalidade. (Unger, 2009, p.7, Grifos nossos).

\section{DA ECONOMIA À SOCIEDADE: a reorganização do Estado e a reorientação da política social}

Os projetos de transformação do Nordeste elaborados por Celso Furtado e Mangabeira Unger compartilham duas preocupações fundamentais, uma de caráter social e outra de natureza política. A primeira dedica-se ao enfrentamento, em seu fundo causal, da chocante desigualdade social do Nordeste. A segunda preocupa-se com a construção do agente institucional capaz de traduzir e desdobrar o projeto em iniciativas concretas e práticas, através de seus múltiplos e complexos níveis políticos e administrativos, no âmbito de nosso aparato estatal e governamental. Essa parte do texto discutirá quais as respostas dadas pelo projeto mais recente encabeçado por Mangabeira Unger a essas temáticas, realçando o contexto teórico de onde elas são extraídas.

Uma das grandes vertentes do projeto de Unger para o Nordeste apresenta, como justificativa da iniciativa, a possibilidade de ela exemplificar um novo tipo de federalismo para o Estado brasileiro, marcado por uma lógica de cooperação estreita entre os três níveis da federação. ${ }^{19} \mathrm{~A}$ ideia básica que suscita essa questão resulta da observa-

${ }^{19}$ Observe-se que Furtado também identificou o nosso federalismo como mais um obstáculo ao desenvolvimento do Nordeste e, de maneira original, refletiu sobre o que designou de "federalismo cooperativo", que, em sua perspectiva, havia sido ensaiado durante a experiência democrática da República de 45 a 64. Segundo um comentarista, "[...] o federalismo cooperativo, nos termos propostos por Furtado, apontava para uma descentralização parcial 
ção de um problema característico de países territorialmente extensos e com desigualdades regionais significativas como o Brasil: a necessidade da compatibilização de padrões nacionais de investimento e de qualidade com a gestão local das políticas públicas. Nessas circunstâncias, é importante que o Estado tenha um bom sistema de monitoramento e de financiamento dessas políticas e flexível o suficiente para ser capaz, inclusive, de reorientar temporariamente, de acordo com necessidades extraordinárias, recursos e quadros de um local para outro. Mas o problema maior é que, mesmo depois desses ajustes, uma determinada área da política pública pode ostentar índices abaixo dos padrões mínimos aceitáveis estabelecidos. Nesse caso, qual seria a solução? Na resposta de Unger, o Estado tem de constituir uma instância transfederal que reúna os três níveis da federação e que tenha poder de intervenção nessa área da política pública que enfrenta dificuldades, para saneála e devolvê-la consertada ao ente federado constitucionalmente responsável. O espírito é fortalecer o experimentalismo através da cooperação.

Uma das premissas norteadoras desse federalismo cooperativo parte de uma constatação teórica acerca da necessidade de transformação do Estado, face às mudanças nos paradigmas de organização da produção, numa direção "pós-fordista”, que cada vez mais invade os espaços da vida social, tornando ainda mais inadequados muitos dos meios com que o Estado, fundado numa lógica "fordista" de excessiva padronização e rigidez, ainda opera na realização de suas ações. Um exemplo dessa circunstância pode ser observado na necessidade de reforma da relação da sociedade civil com o Estado, no que diz respeito à provisão das políticas públicas. Vários especialistas definem os serviços públicos ofertados pelo Estado, em quase

na aplicação dos recursos públicos federais nos estadosmembros, o que seria feito pelas instituições regionais federais, por estar apoiado nas influências teóricas de um planejamento não autoritário. Entretanto, o desenvolvimento econômico equilibrado, para Furtado, dependia muito mais das iniciativas da União que das unidades subnacionais, ou mesmo da participação social. Era decisivo o papel do governo federal na construção da ordem ideal, o que significava um afastamento do modelo americano clássico.” (Ismael, 2009, p. 236). todos os países, como uma espécie de "fordismo administrativo", pela sua característica padronização, ao que se associa a falta de qualidade - embora, para os mais objetivos, isso pouca relação guarda com a questão do estilo de organização, como apregoam os liberais em seu jargão sobre gestão. Na esteira dessa argumentação, Unger rejeita, inclusive, como falta de imaginação institucional, a ideia de que a alternativa a esse "fordismo administrativo" seja a provisão privada desses serviços. ${ }^{20}$

Mas a proposta institucional de reconstrução do federalismo, além de trazer a ideia de substituição da repartição rígida de competências entre os três níveis da federação por um "federalismo cooperativo", que associe os entes federados em experimentos compartilhados, traz outra questão, ligada à ampliação do potencial de uma determinada localidade ou setor: divergir do modelo jurídico e institucional constituído e construir uma espécie de contra modelo, que pode vir a ser o modelo do futuro. ${ }^{21} \mathrm{O}$ que inibe essa possibilidade, no federalismo clássico, é que, ao dar liberdade para uma região ou um setor, imagina-se a necessidade de oferecer liberdade igual para todos. Mas essa circunstância não é necessária. É possível imaginar que determinadas localidades ou se-

${ }^{20}$ A SAE, sob o comando de Mangabeira Unger, tentou levar a cabo também um projeto de ampla reformulação da administração pública como elemento importante da construção de um modelo de desenvolvimento. A ideia básica é que a reforma do Estado não deve restringir-se à mera transposição das práticas mais características da gestão privada para o aparato estatal, e nem desvincular o debate sobre o conteúdo dessa reforma do Estado da discussão sobre o modelo de desenvolvimento que o Estado, uma vez reformado, tornar-se-á instrumento. A SAE produziu um texto com toda essa problematização, no qual sustentava que o verdadeiro choque de gestão no país significava realizar simultaneamente três agendas inacabadas em matéria de administração: a da profissionalização, a da eficiência e a do experimentalismo (Secretaria de Assuntos Estratégicos, 2009). O princípio teórico sugerido é que o contraste hidráulico da política do século XX, na qual mais Estado implica menos mercado e vice-versa, deva ser superado numa perspectiva progressista (Unger, 1999).

${ }^{21}$ Esse é o caso, por exemplo, da política industrial e agrícola voltada para os pequenos e médios empreendedores, em que um dos aspectos da relação entre o Estado e os produtores expressa o princípio da cooperação federativa. O mesmo raciocínio, ainda que com muito mais intensidade, vale para áreas como educação e saúde. Sob esse aspecto, o SUS é uma empreitada institucional que contempla o espírito da ideia em tela. Para uma apreciação do espírito da ideia de federalismo cooperativo aplicada ao caso das políticas públicas do Estado brasileiro, ver Chaves (2010). 
tores tenham poderes extraordinários de divergências da orientação geral. Isso implicaria a realização da ideologia experimentalista que inspira o federalismo clássico, mas que, no entanto, não tem sido praticada. Trata-se da percepção dos estados federados como laboratórios de inovações. ${ }^{22}$

No bojo dessa proposta de reconstrução do federalismo brasileiro, o projeto Nordeste formulado por Unger desdobra-se rumo à questão da capacitação da enorme população desprovida de capital cultural, tendo em vista, sobretudo, duas prioridades: a primeira é assegurar, dentro de um país muito grande, muito desigual e de regime federativo, a reconciliação da gestão local dos sistemas escolares pelos estados e municípios, com padrões nacionais de investimento e de qualidade. Sem a participação decisiva da União, o Nordeste não construirá a escola capaz de realizar o choque de ciência e tecnologia exigido como contrapartida das transformações econômicas sugeridas anteriormente. Ea segunda é aproveitar o impulso dado pelo governo Lula ao ensino técnico para enfrentar, simultaneamente, dois desafios: a) usar a rede federal de escolas técnicas para soerguer o elo fraco do sistema escolar brasileiro, que é o ensino médio, cuja responsabilidade de gestão recai sobre os estados e municípios; b) usar as escolas técnicas para construir uma fronteira aberta entre o ensino geral e o ensino técnico. Mas ele adverte: "Convém fazer tudo isso com largueza de visão, livre das restrições impostas pelo imediatismo. Os enigmas do Nordeste podem inspirar avanços científicos e inovações tecnológicas cuja utilidade prática só aparecerá adiante" (Unger, 2009, p. 20-21). ${ }^{23}$

Essa junção, por sua vez, enseja a insistên-

${ }^{22}$ A ideologia do federalismo clássico norte-americano apregoa a ideia de que os Estados federados atuem, em alguma medida, como laboratórios de experimentação de projetos e caminhos distintos daquele do governo central, embora a sua prática institucional fundada na repartição rígida de atribuições entre os entes federados contradiga frontalmente o princípio manifesto da ideologia. Para uma apreciação dessa discussão, face ao tema do federalismo cooperativo, ver Dorf; Sabel (1998, p. 292-313.

${ }^{23} \mathrm{O}$ texto do projeto Nordeste diz: "A política industria voltada para redes de pequenas e médias empresas industriais, e tanto para a agricultura irrigada como para a de sequeiro, são provocações naturais para mobilizar ciência e tecnologia. Falta o agente institucional. Já existe porém, base de apoio financeiro no Sibratec - o novo Sistema Brasileiro de Tecnologia. Para qualificar-se ao cia em transformar o modo de ensinar: substituir o modelo pedagógico baseado na informação por um tipo de ensino que seja mais analítico. Na verdade, essa sua proposta significa antecipar para as primeiras etapas da aprendizagem o trabalho cooperativo que caracteriza os estágios mais avançados da ciência. A crença no poder social da educação, evidenciada por grandes pensadores liberais, como John Dewey e Bertrand Russell, é fortemente compartilhada por Unger. Um dos temas caros ao seu pensamento programático é aquele referente às ideias sobre uma forma de ensino que resgate a criança das limitações de seu meio - de sua família, de sua classe social, de seu tempo histórico, de sua cultura nacional - e lhe dê os instrumentos da resistência moral e da antevisão intelectual (Unger, 1999, p. 180-185). ${ }^{24}$

O segundo eixo analítico do desdobramento programático do projeto Nordeste apresentado por Mangabeira Unger emerge no contexto da discussão que se tornou conhecida no Brasil como a "porta de saída" dos programas de transferência de renda, comumente proposta pelos representantes intelectuais e políticos da direita. A ideia básica é a que os programas de transferência, como o programa Bolsa Família, são resgates de cidadania, já que, na miséria, as pessoas são imobilizadas inclusive pelo medo. Dessa forma, os programas de transferência devem ser entendidos como instrumentos que criam as condições para uma mobilização mínima (Vanderbouth; Parijs, 2006). O que Unger diz em resposta é que as transferências representam uma condição necessária, mas não uma condição suficiente. E que, portanto, deveria

apoio que, por meio dele, virá da Finep e de outras entidades federais e estaduais, deve cada um dos estados nordestinos organizar uma entidade - ou aproveitar entidade existente - para coordenar o trabalho de identificação, desenvolvimento, adaptação e transferência das tecnologias mais relevantes - relevantes, sobretudo, para as iniciativas industriais e agrícolas enumeradas anteriormente” (Unger, 2009, p. 20).

${ }^{24}$ No panorama da educação brasileira, a identificação de Unger é com a perspectiva pedagógica de Anísio Teixeira que, além de discípulo do experimentalismo de Dewey, como o próprio Unger, foi secretário de educação do Estado da Bahia na época em que Otávio Mangabeira, seu avô, foi governador. Anísio Teixeira exerceu também grande influência sobre Darcy Ribeiro, e um de seus principais projetos, o CIEP, foi implementado no estado do Rio de Janeiro durante os governos de Leonel Brizola nas décadas de 80 e 90. 
haver uma versão progressista - que não há - dessa discussão sobre as "portas de saída”, descritas por outra linguagem que enfatizasse a necessidade de agregar elementos de ampliação da oportunidade e de capacitação a esses programas.

A ideia se baseia num dado empírico sobre a estrutura de classes no Brasil e sobre o perfil dos beneficiários dos programas de transferência como o Bolsa Família. Quando se observam os dados recentes a respeito da evolução da renda e de seus componentes no Brasil, verifica-se o seguinte: embaixo, entre aqueles descritos por Jessé Souza como a "ralé" brasileira, houve um crescimento da renda, sem que tenha havido um crescimento da renda do trabalho. Entende-se que a maior parte desse crescimento se deve aos programas de transferência de renda. Mais adiante, no gráfico de evolução da renda, houve um crescimento da renda menor, mas uma proporção muito maior desse crescimento devido à renda do trabalho. $\mathrm{E}$ a partir daí, a curva continua a descender (Paes de Barros, 2008).

Essa constatação empírica inspirou a seguinte conjectura causal: entre o núcleo duro da pobreza, de um lado, e a pequena burguesia empreendedora, de outro, haveria um grupo intermediário, que Unger chamou de "batalhadores". Esse grupo social seria composto basicamente por pessoas que surgem mais ou menos no mesmo meio pobre da "ralé", do núcleo da pobreza, mas que, por razões sociológicas e psicológicas especiais, responderam às duríssimas circunstâncias coletivas e conseguiram iniciar seu autorresgate. De acordo com essa ideia, essas pessoas existem aos milhões no Brasil, no Nordeste principalmente. Essa hipótese a respeito da estrutura de classes inspirou uma sugestão programática: o desdobramento capacitador dos programas de transferência teria de ter em vista essa diferença entre a "ralé" e esse grupo chamado de "batalhadores". O núcleo duro da pobreza é composto por pessoas que estão cercadas por um conjunto de inibições familiares e culturais, o que dificulta a eficácia dos programas de capacitação. A experiência mundial de programas de capacitação dirigidos a esse núcleo duro da miséria é desalentadora, conforme estudos como o de Galasso (2006) e Rodrigues (2010).

Portanto, o malogro se explicaria por causa desse conjunto de inibições sociais e culturais. Para a "ralé", não funcionaria uma iniciativa direta de capacitação. A primeira coisa a fazer é assegurar que o Estado consiga assumir algumas das funções das famílias desestruturadas e adensar o sistema de assistência social. Isso não objetiva substituir a família, mas complementá-la. Já os "batalhadores" seriam os alvos naturais dos programas de capacitação, na medida em que já demonstraram que são resgatáveis, por uma razão simples: já iniciaram o seu próprio resgate. De acordo com essa perspectiva, o equívoco comum que se comete no mundo é dirigir os programas de capacitação aos mais pobres. Embora seja compreensível pensar que a capacitação deva começar pelos mais carentes, a lógica da política não deve ser a mesma da caridade. Então, paradoxalmente, os programas de capacitação deveriam começar não pelos mais carentes, mas pelos relativamente menos carentes, que funcionariam como uma espécie de "vanguarda" do contingente mais pobre de pessoas que viria em seguida.

\section{CONSIDERAÇÕES FINAIS}

Independentemente de se concordar ou não com as ideias norteadoras dos projetos encabeçados por Celso Furtado e Mangabeira Unger, há de se reconhecer que ambos se caracterizaram pelo compartilhamento da visão de que a melhor maneira de compreender as possibilidades do futuro é influir na sua construção. Para isso, o pensamento e a ação não podem prescindir da combinação de três atributos fundamentais: realismo, generosidade e ousadia. Na política contemporânea, o realismo passou a ser identificado com a aceitação dos preconceitos e interesses da ordem estabelecida. Para esses dois pensadores brasileiros, realista é o agente que tanto se dispõe a compreender e enfrentar a realidade, sem desconsiderar nem superdimensionar seus elementos refratários e constrangedores, como aquele que, por atuar sobre 
ela, acaba virando um visionário capaz de enxergar também as possibilidades de transformação dessa realidade, sempre ambivalente e contraditória. Entendido dessa maneira, e aplicado ao Nordeste, o realismo casa-se com a generosidade e a ousadia. Essas foram as grandes marcas dos projetos de Nordeste liderados pelos dois estrategistas: "O Nordeste é o maior órfão do modelo de desenvolvimento construído no país no último meio século. Convém ao país que o Nordeste se rebele contra esse modelo de desenvolvimento. Ao se rebelar contra ele, falará pelo Brasil.” (Unger, 2009, p. 22).

Recebido para publicação em 15 de outubro de 2012 Aceito em 26 de agosto de 2013

\section{REFERÊNCIAS}

BACELAR, Tânia. A questão regional e a questão nordestina. In: TAVARES, M. C. (Org.) Celso Furtado e o Brasil. São Paulo: Perseu Abramo, 2000.

Desenvolvimento regional no Brasil. In: FURTADO, Celso et al. O pensamento de Celso Furtado e o Nordeste hoje. Rio de Janeiro: Contraponto, 2009.

CASSIOLATO, José; MATOS, Marcelo; LASTRES, Helena (Org.) Arranjos produtivos locais. Uma alternativa para o desenvolvimento. Rio de Janeiro: E-Papers, 2008.

CEPEDA, Vera. O pensamento político de Celso Furtado: desenvolvimento e democracia. In: PEREIRA-BRESSER, L. C.; REGO, J. M. (Org.) A grande esperança em Celso Furtado. São Paulo: Editora 34, 2001.

CHAVES, Vitor. Políticas públicas e reconstrucão do federalismo brasileiro. São Paulo: Interesse Nacional, 2010. v. 9.

CUI, Zhyuan. Prefácio. In: UNGER, R. M. Política. São Paulo: Boitempo, 2001.

DORF, Michael; SABEL, Charles. The constitution of democratic experimentalism, Columbia Law Review, New York, n.267, 1998.

FIORI, José Luís. O projeto de "desenvolvimentismo nacional, popular e igualitário”, sintetizado pelo Plano Trienal de Celso Furtado de 1963, foi bloqueado pelo golpe militar de 1964. Revista Reportagem, Brasília, UNB, fev. 2004.

FURTADO, Celso. A operação Nordeste. Rio de Janeiro: ISEB, 1959.

Uma política de desenvolvimento econômico para o Nordeste. Recife: SUDENE, 1967.

. Obra autobiográfica. São Paulo: Paz e Terra, 1997.

GALASSO, Manuela. With their Effort and one opportunity Alleviating Extreme Poverty in Chile. Developmente Research Group - World Bank, Washington, DC, World Bank, 2006.

ISMAEL, Ricardo. Celso Furtado e a redefinição do fede- ralismo brasileiro. In: FURTADO, Celso et al. O pensamento de Celso Furtado e o Nordeste hoje. Rio de Janeiro: Contraponto, 2009.

LOURENCO, Alberto. Estado e competitividade territorial espontânea: a esfinge em Jardim de Piranhas. Boletim Regional. Informativo da Política Nacional de Desenvolvimento Regional, Brasília, Ministério da Integração Nacional, n. 4, maio/ago, 2007.

MARANHÃO, Silvio (Org.) A questão Nordeste. Rio de Janeiro: Paz e Terra, 1982.

MYTELKA, L.; FARINELLI, F. De aglomerados locais a sistemas de inovação. In: LASTRES, H.; CASSIOLATO, J.E.; ARROIO, A. (Org.) Conhecimento, sistemas de inovação e desenvolvimento. Rio de Janeiro: Contraponto, 2005 .

OLIVEIRA, Francisco. Elegia para uma re(li)gião: SUDENE, nordeste, planejamento e conflito de classes. Rio de Janeiro: Paz e Terra, 1977.

PAES DE BARROS, Ricardo et al. A dinâmica da desigualdade no Brasil e seus principais determinantes. Brasília: IPEA, 2008.

PESSÔA, Samuel. Existe um problema de desigualdade regional no Brasil? Salvador: ANPEC, 2001.

RODRIGUES, Eduardo. Escassos caminhos: os processos de imobilização social dos beneficiários do rendimento social de inserção. Porto,Pt: Edições Afrontamento, 2010 .

SOUZA, Jessé. Os batalhadores brasileiros. Nova classe média ou nova classe trabalhadora? Belo Horizonte: Ed. da UFMG, 2010.

TEIXEIRA, Aloisio. Utópicos, heréticos e malditos. Os precursores do pensamento social de nossa época. Rio de Janeiro, Record, 2002.

UNGER, Roberto Mangabeira. O desenvolvimento do Nordeste como projeto nacional. Brasília: Secretaria de Assuntos Estratégicos, 2009.

O direito e o futuro da democracia. São Paulo: $\overline{\text { Boitempo, } 2004 .}$

Furtado e futuro. Folha de São Paulo, São Paulo, 23 nov. $2004 \mathrm{~b}$.

Democracia realizada - a alternativa progressista. São Paulo: Boitempo, 1999.

VANDERBOUGHT, Y.; PARIJS, P. Renda de cidadania: argumentos éticos e econômicos. Rio de Janeiro: Civilização Brasileira, 2006 [1999]. 


\section{THE POLITICAL ECONOMY OF THE TRANSFORMATION OF THE NORTHEAST: from Furtado to Unger}

\author{
Carlos Sávio Teixeira
}

This paper analyzes two proposals of structural reorganization of northeastern society, prepared at different moments in time, one under Celso Furtado's intellectual leadership and the other under Mangabeira Unger's leadership. It argues that both stem from the premise that the fight against the serious problems faced by the country's most unequal region requires bold institutional reconstruction, as well as the adoption of public policies that confront the structural constraints of the region, rather than just lessen them. It reinforces the idea that the project that gave origin to SUDENE (Superintendence for the Development of the Northeast), headed by Furtado, served as inspiration to the second latest venture, since the two initiatives were based on ideas that surpass a merely redistributivist perspective.

KEY wORDs: Northeast, structural change, institutional reconstruction, Celso Furtado, Mangabeira Unger.

\section{LÉCONOMIE POLITIQUE DE LA TRANSFORMATION DU NORD-EST: de Furtado à Unger}

Carlos Sávio Teixeira

Cet article analyse deux propositions de réorganisation structurelle de la société du nordest élaborées à des moments différents, l'une sous le leadership intellectuel de Celso Furtado et l'autre de Mangabeira Unger. On y argumente que toutes deux partent de la prémisse selon laquelle les affrontement des graves problèmes de la région la plus inégalitaire du pays suppose une reconstruction institutionnelle courageuse ainsi que l'adoption de politiques publiques prêtes à affronter les contraintes structurelles de la région et non pas seulement les atténuer. On y affirme que la proposition qui a donné naissance à la SUDENE, menée par Furtado, a servi d'inspiration à une deuxième entreprise plus récente, ces deux initiatives étant fondées sur des idées allant audelà d'une perspective purement distributive.

Mots-CLÉs: Nord-est, changement structurel, reconstruction institutionnelle, Celso Furtado, Mangabeira Unger.

Carlos Sávio Teixeira - Doutor em Ciência Política. Professor adjunto do departamento de Ciência Política da UFF onde atua na graduação de ciências sociais e no programa de pós-graduação em Ciência Política. Participa de um grupo de pesquisa internacional em parceria com o Instituto de Estudos da Ásia e África da Universidade de Humboldt em Berlim. Tem dois livros publicados: um que analisa a relação entre mídia e política e outro que é fruto de uma organização de textos do filósofo Roberto Mangabeira Unger. Tem, também, dois livros no prelo: um em co-organização com o sociólogo Jessé Souza sobre as transformações recentes da sociedade nordestina e outro resultado de sua tese de doutorado. 